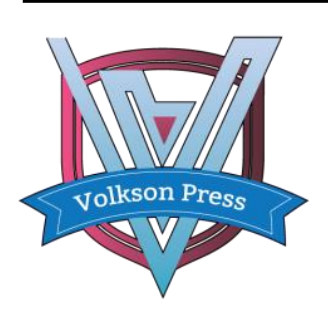

\title{
RESEARCH PROGRESS OF PHENOTHIAZINE COMPOUNDS OF DIOXOPROMETHAZINE HYDROCHLORIDE
}

\author{
Tingting Zhao, Chuanbo Dai*, Yuting Gao \\ Institute of Petroleum and Chemical, Jilin Institute of Chemical Technology, \\ Jilin City 132022, China. \\ *Corresponding Author Email: daichb@163.com
}

This is an open access article distributed under the Creative Commons Attribution License, which permits unrestricted use, distribution, and reproduction in any medium, provided the original work is properly cited

\section{ARTICLE DETAILS}

\section{Article History:}

Received 26 June 2018 Accepted 2 July 2018

Available online 1 August 2018

\begin{abstract}
With the development of science and technology and the progress of society, people are paying more attention to the environment and energy while paying attention to production and benefits. Phenothiazine compounds are very important heterocyclic compounds. They have been widely used in medicine, electroluminescent materials, solar cells, polymerization inhibitors, antioxidants, antioxidants and other fields in recent years. This article briefly introduces the application and technological progress of phenothiazine compounds. Dioxopromazine hydrochloride is a type of phenothiazine compounds, which have high application and research value in the aspects of relieving cough, relieving asthma, eliminating phlegm, antihistamine and so on. In this paper, we will summarize the oxidation processes commonly used in the production of dioxaprozin hydrochloride to make it more green and efficient,and provide a reference for the development of dioxopromazine hydrochloride, and look forward to the future production process and research direction.
\end{abstract}

\section{KEYWORDS}

Phenothiazine, Dioxopromethazine hydrochloride, Oxidation reaction, Synthesis .

\section{INTRODUCTION}

\subsection{Phenothiazine compounds}

Phenothiazine is an organic aromatic compound composed of a sulfur atom and a nitrogen atom connecting two benzene rings (phenothiazine parent nucleus). It is sublimating, has a faint odor, is irritating to the skin, can cause rashes, can also be absorbed through the skin and cause visceral disorders. Phenothiazine as an intermediate in the manufacture of methylene blue dyes, which can also be used to make a class of important antihistamines and antihistamines such as chlorpromazine, perphenazine, is opropyrazine and dioxpromazine hydrochloride [1-5] In addition, phenothiazine can also be used as inhibitors of vinyl acetate, raw materials for rubber antioxidants, synthetic dyes, drugs, fruit tree insecticides and livestock repellents.

The formula is as follows(figure1):<smiles>c1ccc2c(c1)Nc1ccccc1S2</smiles>

Figure 1: Phenothiazine structure

Phenothiazide is a very important heterocyclic compound, which is widely used. In recent years, a large number of studies have shown that phenothiazine compounds have a certain role in anti-cancer and antifungal due to their biological activity [6]. Phenothiazine compounds are not only good bioactivity, but also the main ingredients of some drugs, and are also good raw materials for photosensitized solar cells. It can also be added to petroleum products as antioxidants to improve the damage to machinery such as gasoline and lubricants [7]. At the same time, phenothiazine compounds can also be used for antiviral, polymerization inhibitors and so on.

\subsection{Dioxopromethazine hydrochloride}

Dioxopromethazine hydrochloride, whose chemical called: 1-(5,5dioxophenothiazin -10-yl) -N,N-dimethylpropan-2-amine, were invented by German democratic republic in 1967, 1970 is applied in clinical, with the structure of phenothiazine, It is the sulfone that is oxidized in the body by isopropyl [8]. This product is a white or yellowish powder or crystalline powder, odourless, taste bitter, soluble in water, slightly soluble in ethanol. The chemical structure of dioxoprozin hydrochloride is similar to the structure of promethazine, but the difference is that $\mathrm{S}$ has two more oxygen atoms than the latter. Its pharmacological effects are similar to those of promethazine, both have strong antihistamine and antiallergic effects, and have certain anti-inflammatory effects [9-11]. However, different from promethazine, the drug has a strong antitussive effect, and has a weak central nervous system sedative and hypnotic effect. Pharmacological experiments have proved that the drug has no damage to liver, kidney and hematopoietic organs. The formula is as follows (figure 2):<smiles>CC(C)CN(c1ccccc1C(=O)c1ccccc1)C(C)C</smiles>

Figure 2: Dioxopromethazine hydrochloride structure 
Dioxazine hydrochloride has a strong antitussive effect, its antitussive mechanism is mainly due to the inhibition of the coordination of the cough center and local spasm, its antitussive effect is strong, the effective time is fast, long-term maintenance, no obvious Side effects, no addiction, no thick ringworm, inhibition of breathing, repeated symptoms and other shortcomings [12]. Its antitussive intensity is 6-11 times that of codeine, $30-40$ times that of cough, and a duration of 4-6 hours. Dioxprozine hydrochloride also has antihistamine and anti-allergic effects. Antihistamine effects have a strong preventive effect on tissue-induced asthma and a strong antispasmodic effect on histamine-induced isolated smooth muscle spasm. In addition, there is a certain role of antiinflammatory and local anesthesia [13]. In the clinical application of acute and chronic bronchitis and various diseases caused by cough, urticaria, pruritus and other symptoms of treatment.

\section{SYNTHESIS PROCESS}

\subsection{Phenothiazine synthesis process}

In 1883, the German chemist Bernthsen reported on the synthesis of phenothiazine using diphenylamine and sulfur as the reaction substrates under high temperature conditions. This is the first time that the phenothiazine synthesis method has been reported [14]. For many years to come, this traditional route was the dominant method for the synthesis of phenothiazines. However, this method takes a long time and is often accompanied by the production of two positionally isomeric products. The two products have similar properties and the product is not easily purified.

With the exploration of the biological activity of phenothiazine compounds, more and more researchers are devoted to exploring new phenothiazine synthesis methods. Below, we will introduce different phenothiazine synthesis methods.

Vasile et al. use iodine as a catalyst for the reaction and use microwave radiation to heat the reaction between diphenylamine and sulfur. Activation of electrons shortens the reaction time of the reaction, improves the efficiency, and achieves better yields.<smiles></smiles>

Figure 3: Diphenylamine and sulfur were synthesized by iodine catalysis. Ma Dawei's task group used 2-iodoaniline and 2-bromothiophenol as raw materials to synthesize phenothiazine compounds (see figure 4) However, there are two reaction centers where both materials can be coupled, so the reaction is often accompanied by four possible products, two of which are self-couplings from the raw materials, and two products are cross-coupled products.<smiles>Nc1ccccc1I</smiles>

Figure 4: Reaction of 2-iodoaniline with 2-bromobenzenethiol-catalyzed reaction to form phenothiazine

Yiqian Wan research group reported the use of a divalent cupric salt and $\mathrm{N}$ - methyl - pyrrole-2-carboxamide interaction catalytic system, completing the synthesis of phenothiazine two routes [15-17]. The raw materials are 2-iodoaniline and 2-bromoaniline, see figure 5; 0 aminothiophenol and ortho-arylene dihalides, see figure 6. The temperature of the reaction was $90^{\circ} \mathrm{C}$, and it was found that the catalytic system formed by the cupric salt and $\mathrm{N}$-methyl-pyrrol-2-amide during the reaction had an effect on promoting the arylation of aromatic amines, fatty amines, and ammonia water.

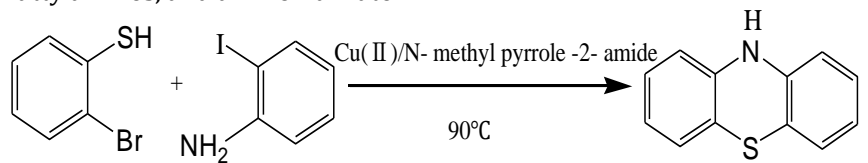

Figure 5: Copper-catalyzed reaction of 2-bromothiophenol with 2iodoaniline to phenothiazine

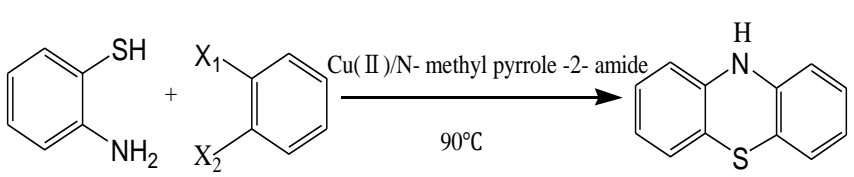

Figure 6: Copper-catalyzed reaction of o-aminothiophenol and aryl dihalide to phenothiazine

Weiye $\mathrm{Hu}$ synthesized phenothiazine with $\mathrm{FeSO}_{4} \cdot 7 \mathrm{H}_{2} \mathrm{O}$ as catalyst. As shown in figure 7.

This method was used to replace the copper and palladium catalysts used in the previous use, and it was good, and the maximum yield was 96\%. However, when phenothiazine is synthesized in this method, two phenothiazine isomers with similar properties can be produced in some substrate reactions.<smiles>[R2]c1ccc2c(c1)Sc1ccc(Br)cc1N2</smiles>

Figure 7: Fe catalyzed reaction of acetaminophen and ortho aryl two halides to phenothiazine.

In 2016, Zhang S L and others synthesized phenothiazine compounds in the environment without transition metal catalysis. They used N- (2iodide) acetamide and 2- Bromophenyl alcohol (2- chlorophenol) as raw materials, which were produced by $\mathrm{C}-\mathrm{N}$ coupling and $\mathrm{C}-\mathrm{N}$ coupling reaction in series $[18,19]$. The use of potassium carbonate in reaction. Phenothiazine was obtained as a base in a solvent DMF for 48 hours, as shown in figure 8 . The method is simple and efficient for the synthesis of phenothiazine compounds without catalyst and ligand.But the reaction time is $48 \mathrm{~h}$, the required reaction time is longer, and the 2 - bromide thiol (2- chloro phenyl thiol) used in the reaction is volatile, accompanied by a strong smell.

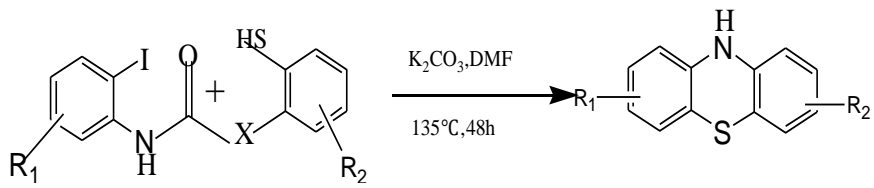

Figure 8: Synthesis of phenothiazine from N-(2-iodophenyl) acetamides and o-halothiophenol

\subsection{Dioxopromethazine hydrochloride oxidation method}

Dioxopromethazine hydrochloride is widely used, which is combined with other reagents to produce more powerful products. Research shows that the envelope reaction of $\beta$ - cyclodextrin and two dioxopromethazine hydrochloride can occur under certain conditions, and the fluorescence sensitization and fluorescence quenching can be displayed at different concentration ratios [20]. The effect of macroporous polystyrene sulfonic acid - dioxalazine complex is stronger than that of low molecular dioxazine, and it lasts longer and reduces toxicity than before. The synergistic effect of two dioxopromethazine hydrochloride and some natural products can be used for the treatment of cholelithiasis. The methods of detection mainly include fluorescence analysis, UV spectrophotometry, high performance capillary electrophoresis, flow injection chemiluminescence, high performance liquid chromatography and molecular imprinting electrode for the direct determination of two dioxopromethazine hydrochloride.

Because the structure of dioxopromethazine hydrochloride is similar to the structure of promethazine hydrochloride. So, dioxopromethazine hydrochloride is mostly obtained by oxidation of promethazine hydrochloride.

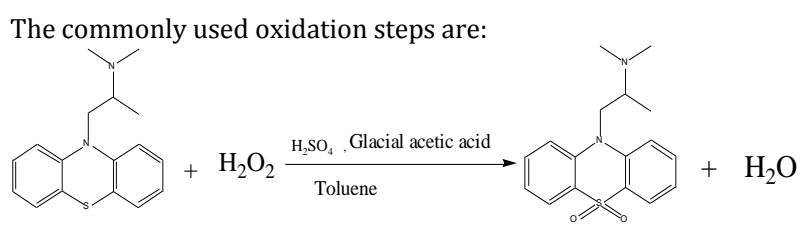

Figure 9: Oxidation of promethazine by hydrogen peroxide

In a $250 \mathrm{ml}$ glass jar, $104.6 \mathrm{~g}$ of glacial acetic acid and $16.8 \mathrm{~g}$ of promethazine were weighed in order, stirring was started, and the 
temperature was raised to $40^{\circ} \mathrm{C}$ to complete dissolution. Cool down to 25 ${ }^{\circ} \mathrm{C}$, slowly add concentrated sulfuric acid $3.7 \mathrm{~g}$, control the speed, add about 10 minutes, while maintaining the liquid temperature at $25{ }^{\circ} \mathrm{C}$ Slowly add hydrogen peroxide solution 16.8g, add up in about 1 hours. At the same time, the liquid temperature is maintained at 25 thermal insulation reaction 0.5 hours. Slowly warm up to 68 and keep the reaction for 10 hours. When cooling to 25 centigrade, add 50.4 drinking water Keep the liquid temperature at $25 \mathrm{C}$, add the lye slowly, and modulate the pH by 13. Add $168 \mathrm{~g}$ toluene, stirring for 10 minutes, and after 10 minutes, divide the water layer. The toluene layer was added to drinking water and washed to $\mathrm{pH}$ for 7 . Toluene solution of dioxoprothazinwas pumped into a distilling tank to recover toluene by decompression and obtain yellow or white wax dioxoprothazin.

A green process oxidation step:

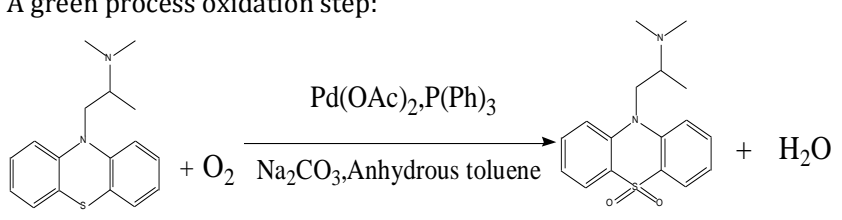

Figure 10: Oxygen oxidation of promethazine

Promethazine, anhydrous sodium carbonate, palladium acetate and three phenyl phosphine were added to two dry flasks, and anhydrous toluene was added as the reaction solvent, and the velocity of $6-10 \mathrm{~m} / \mathrm{s}$ at the velocity of oxygen was added, and the substrate isopromethazine was heated to $60-85 \mathrm{C}$ for 18 hours: three phenylphosphine: the molar ratio of sodium anhydrous sodium was 1:0.5:4. The amount of palladium acetate is $2 \%$ of the mole of promethazine. After the reaction ended, two chloro toluene was extracted with three reaction liquid, combined with extraction solution and dried with anhydrous Magnesium Sulfate, decompressing and drying, and drying the target product dioxoprothazin [21].

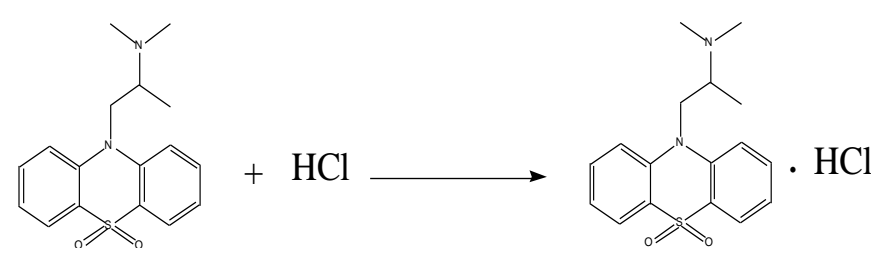

Figure 11: Reaction of dioxopromazine with hydrochloric acid

Add dioxoprothazin and acetone in three flask and stir on magnetic stirrer until the material is dissolved completely until the temperature drops to 18-24 C after the end of the feeding. In order to keep the liquid temperature and slowly add the configured acetone chloride solution to $\mathrm{pH} 4-5$, the solution is stirred to get gray, cloudy dioxopromethazine hydrochloride solution, adding activated carbon, stirring and decolorizing, leaching the cake with acetone, and combining the lotion into the decolorization solution of dioxopromethazine hydrochloride [22]. The white solid

hydrochloric acid two oxazoxide was obtained by vacuum extraction. The commonly used oxidation step requires the use of strong corrosive or toxic liquids such as concentrated sulfuric acid and hydrogen peroxide, which makes its work in terms of production safety and waste liquid treatment more difficult. The method using oxygen as the oxidant and palladium acetate as the catalyst does not require the addition of sulfuric acid and hydrogen peroxide, and the yield is also increased, which has many advantages such as cost reduction, safety, and energy conservation [23]. The yield of this method is higher and more accords with the green reaction of modern chemical production.

\section{EXPECTATION}

Dioxopromethazine dydrochloride has antitussive and antiasthmatic expectorant, anti-gallamine and local anesthetic effects. It has strong antitussive effect and is comparable to codeine. However, the deeper understanding and understanding of dioxopromethazine hydrochloride still need our joint exploration [24]. First, to find a more green process to prepare dioxopromethazine hydrochloride. Secondly, we will further study the effect of dioxopromethazine hydrochloride in combination with other agents.

\section{ACKNOWLEDGMENTS}

I would like to express my sincere appreciation to my supervisor, Mr Dai, for his academic guidance and personal support through every phase of this dissertation, and also for her encouraging my accomplishment of the whole research. I also want to thank many students for their help and valuable suggestions. Finally, I would like to express my heartfelt thanks to all the experts who took time in the busy schedule to review and comment on this article.

\section{REFERENCE}

[1] Luo, J.S., Wan, Z.Q., Jia, C.Y. 2016. Recent advances in phenothiazinebased dyes for dye-sensitized solar cells [J]. Chinese Chemical Letters, 27, 1304-1318.

[2] Abdoun II, A., Ledwith, A. 1997. Cationic polymerization photochemically and thermally induced by phenothiazine cation radical salts. Eurpean Polymer Journal, 33, 1671-1677.

[3] Albery, W.J., Foulds, A.W., Hillman, A.R. 1979. Thionine coated electrode for photogalvanic cells [J]. Nature, 282, 793-797.

[4] Gooley, C.M., Keyzerr, H., Setchell, H. 1969. Free Radical Drug Enhancement [J]. Nature, 223, 80.

[5] Yamamura, T., Suzuki, K., Yamaguchi, T., Nishiyama, T. 1997. Chem. Antioxidant Activities of Phenothiazines and Related Compounds: Correlation between the Antioxidant Activities and Dissociation Energies of O-H or N-H Bonds [J]. Bulletin of the Chemical Society of Japan, 70 (2), 413-419.

[6] Jiang, Y.T., Zhang, Q. 2010. Synthesis and Application of Phenothiazines and their Derivatives. Dyestuffs and Coloration, 03, 3541,49 .

[7] Stephen, J.W. 2002. Virus Inactivation in Blood Components by Photoactive Phenothiazine Dyes. Transfusion Medicine Reviews, 16 (1), 61-66.

[8] Melvin, J.Y., Jefferson, R.M. 1992. Phenothiazines as Lipid Peroxidation Inhibitors and Cytoprotective Agents [J]. Journal of Medicinal Chemistry, 35 (4), 716-724.

[9] Zhu, S., Liu, H. 1989. Dioxopromethazine hydrochloride. Modern Applied Drugs, 1 (6), 39-40.

[10] Papg, G., Lee, L.Y. 2002. Summary: Peripheral Phaemacology of Cough. Pulmonary Pharmacology \& Therapeutice, 15, 217-219.

[11] Filip, S.V., Silberg, I.A., Surducan, E. 1998. Microwave-Assisted Phenothiazines Preparation by Thionation of Diphenylamines [J]. Synthetic Communications, 28 (2), 337-345.

[12] Ma, D., Geng, Q., Zhang, H. 2010. Assembly of Substituted Phenothiazines by a Sequentially Controlled CuI/L-Proline-Catalyzed Cascade C S and C N Bond Formation [J]. Angewandte Chemie International Edition, 49 (7), 1291-1294.

[13] Huang, M., Houa, J., Yang, R. 2015. A Catalyst System, Copper/NMethoxy-1H-pyrrole-2-carboxamide, for the Synthesis of Phenothiazines in Poly (ethylene glycol) [J]. Cheminform, 46 (19), 3356-3364.

[14] Hu, W., Zhang, S. 2015. Method for the Synthesis of Phenothiazines via a Domino Iron-Catalyzed C-S/C-N Cross-Coupling Reaction [J]. The Journal of Organic Chemistry, 80, 6128-6132.

[15] Wu, S., Hu, W.Y., Zhang, S.L. 2016. Potassium carbonate-mediated tandem C-S and C-N coupling reaction for the synthesis of phenothiazines under transition-metal-free and ligand-free conditions [J]. RSC Advances, 6 (29), 24257-24260.

[16] Hong, S., Liu, E., Xin, Z.H. 2014. Study on Fluorescence Analysis of Dioxopromethazine and Its Inclusion Reaction with $\beta$-Cyclodextrin Chemistry \& Bioengineering, 10, 47-50.

[17] Zheng, Z.N., Jun, Y. 1986. Synthesis and Pharmacological Properties of Polystyrene Sulfonic Acid and Dioxopromethazine. Petrochemical Engineering, 15, 622-626.

[18] Lu, C. 2016. Pharmaceutical Composition of Dioxopromethazine Hydrochloride and Its Medicinal Use. China,106117305[A], 11-16.

[19] Xu, W., Wei, G.Z., Jun, Z. 2002. Determination of Dissolution of Dioxopromethazine Hydrochloride Tablets. China Pharmaceuticals, 11 (10), 55-56. 
[20] Hua, S.J., Jun, H.S., Dan, T.D., Yu, L.X. 2012. Determination of Dioxyprainethazine Hydrochloride Content in Dioxyprainethazine Hydrochloride Tablets by High Performance Capillary Electrophoresis China Pharmaceuticals, 21 (17), 31-32.

[21] Zhong, W.C., Cheng, Z.L. 2010. Determination of Content and Content Uniformity of Dioxopromethazine Hydrochloride Tablets by HPLC. China Pharmaceuticals, 19 (4), 30.

[22] Wei, Z.Z., Jun, S.G., Shuai, M., Sai, D., Yan, G.L., Jie, G.X. 2015 Preparation and Characteristics of a Molecularly Imprinted Electrode for Dioxopromethazine. Hydrochloride, 34 (2), 178-181.

[23] Bartsch, R., Riedel, H. 1970. Chronic toxicity examination of 9,9dioxopromethazine (Prothanon) on rat. Pharmazie, 25 (2), 97.
[24] Fa, S.Q. 2017. A Green Process for Preparing Dioxyprainethazine Hydrochloride with Oxygen as Oxidant.China,106749098[A]-05-31.

\section{ABOUT THE AUTHORS}

Tingting Zhao (1993-),female,master,mainly engaged in the synthesis of pharmaceutical intermediates

Chuanbo Dai (1972-),male,professor,mainly engaged in the development of chemical process

Yuting Gao (1993-),female,master,mainly engaged in the synthesis of pharmaceutical intermediates 